\title{
Addiction, mental health and dual pathology in geriatrics
}

\begin{abstract}
The mental pathology is not "trending topic" in any forum, prejudices, clichés and destitution by society, forge this a very murky issue, as scientific evidence about it. If addiction is added and the pose in geriatric patients had a total "TABU" Substance abuse at age 50 , will be extended to geriatric ages, a tsunami is approaching. Only in the United States and Canada it is estimated that 2.8 million over 50years with addiction and that by 2020 will be about 5.7 million. ${ }^{1}$ These figures are opaque. Experts talk about this problem is underestimated. If it is clear that these 2.8 million that have not yet reached retirement age, pass shortly geriatric ages and there is the problem of tackling complex.
\end{abstract}

What forced this situation? A demand for services involving detoxification and very probably psychic and active therapy and intensive monitoring of these patients, a reality, coupled to a portion of those suffering from dual pathology (addiction + mental illness). Those public systems can not address this problem and are private insurance, who must consider the situation in planning their "healthcare management in geriatrics". Definitely these needs, involves changes in the coverage of health insurance policies, and increased staff and center for these patients in the acute phase and monitoring of chronically with extremely high costs. So determine where we stand currently allow, guide management strategies in such a situation.

Keywords: addiction, mental health, dual pathology, geriatrics, medical insurance, opioids, cannabis, Uruguay, illegal drugs, elderly
Volume 2 Issue 6 - 2015

\author{
Bruno De Lema Larre \\ High Complexity Foundation, Spain
}

Correspondence: De Lema Bruno, High Complexity Foundation, Pereira, Barcelona, Spain,

Email delemalarre@gmail.com

Received: October 13,2014 | Published: May 26, 2015
Abbreviations: DSM, diagnostic and statistical manual of mental disorders

\section{High complexity foundation}

Control of addictive substances, are increasingly complex, and many countries are opting for certain drugs are legal for use and sale of controlled free-entertainment purposes. By legalizing the form of consumption, they are also consistent with the drug-related business illegally, no longer exist or may be they governments or state whoever controls the production, distribution and sale of drugs. Governments would benefit from revenues from this type of trading, something which already the case for alcohol and snuff.

The case of Uruguay is the most recent. In Uruguay cannabis is looser from the legislative point of view, that the own consumption of snuff which is much stricter. Here we see the paradox of demonizing some and not others as evidence of damage for both is irrefutable. Mental illness is a stigma, depending on the social situation of the sufferer and the definitions of the street. Thus, being depressed, is a widespread and even understandable situation, under social and economic living world situation, but the madness (psychosis) generates fear and rejection, BBs do not know how accurate, understand this disability.

The other aspect of interest is the drug attached to mental illness is what is called dual pathology. This topic is treated unusually still less in geriatric ages. We can see how the world will exist an inversion of the population pyramid, with a trend that will continue with increasing life expectancy and this generation of seniors, next to the geriatric population, the elderly will have substance use the immediate future. ${ }^{2}$

We consider that:

A. Changes in the physiology of aging changes in sensitivity to the effects of drug use.
B. The use of drugs can interact with more frequent use of psychoactive for seniors and elderly drugs. ${ }^{3}$

C. The chronic medical or psychological conditions can be caused or aggravated by drug use.

D. On whether drugs of abuse ultimately generate such modification of brain neurotransmitter systems,${ }^{4}$ which can be very intense for the changes associated with aging, absorption, metabolism and pharmacokinetics of these substances, putting consumers a potential serious neuro toxicity and adverse side effects associated with drugs, being more evident and more lethal, at least one in four seniors have used psychoactive drug abuse and such use is likely to increase as the population ages. ${ }^{5}$

The use of prescription medicines consumed as drugs of abuse are a serious major health problem in the United States. ${ }^{6}$ as shown in the increasing trends in poisoning deaths associated with drugs and emergency room visits Moreover, increasing the supply and availability of controlled substances, either for therapeutic use, prescriptions or pharmacies as unregulated Internet suggest that older adults are at higher risk of exposure to psychoactive drugs. ${ }^{7-10}$

The use of psychoactive drugs in older adults and the elderly, remain a neglected area of research. Existing studies have focused primarily on alcohol use disorders, and there are few comparable empirical data on the use and disorders associated with the use of psychoactive drugs. The American Geriatrics Society has published clinical guidelines for alcohol use disorders in older adults and the elderly; ${ }^{11}$ however, this does not exist for psychoactive drugs. A better understanding of the problems would allow early identification of and intervene in the use and abuse of psychoactive drugs in this vulnerable population.

Overall, $9.4 \%$ of adults in terms of the US and Canada from 50 to 60 years for 2007 used an illicit drug in the last year. The characteristics 
of this group were male, unpaired (separated, divorced, widowed) early onset of drug use, basic education, low income, unemployment, disability and impaired mental sphere basically major depression in the past year. ${ }^{12}$ The use of prescription drugs for medical purposes was opioids, followed by benzodiazepines, which are among the most prescribed drugs both by psychiatrists and GPs.

Voyer et al., ${ }^{13}$ in a recent Canadian survey relate mental pathology in this case, cognitive impairment, panic attacks, suicidal ideation and major depression, and abuse of benzodiazepines in patients over 65years hence have dual pathology. ${ }^{13}$ Rosen et al. ${ }^{14}$ conducted studies in methadone patients older than 50years. ${ }^{14}$ Their results revealed a high rate $(57 \%)$ of mental disorders in this group of patients, where major depression, 33\% PTSD, 28\% were presented; generalized anxiety disorder, $30 \%$ Urine tests were used to determine the prevalence of drug use (barbiturates, benzodiazepines, cocaine, opiates and amphetamines), ${ }^{15}$ among patients aged 65 years or more in the psychiatric emergency services (Woo and Chen, 2010).

More than 1 in 4 elderly patients $(27 \%)$ had positive urine toxicology. The vast majority (93\%) also had a psychiatric diagnosis (psychosis, depression, anxiety disorder) ${ }^{16}$ suggesting that the use of psychoactive drugs can be highly prevalent among older psychiatric patients (dual pathology). Substance abuse among older adults and individuals in geriatric patients has been described as an invisible epidemic, because the use and substance abuse and mental disorders tend to be poorly recognized, but rarely diagnosed and treated. ${ }^{17}$

The reasons for this range from insufficient knowledge of the subject, the lack of complicity for the patient explain this to your doctor or other health area, the huge rush of visitors, stigma or shame about eating substances, a general reluctance to seek professional help, lack of financial resources or transportation, comorbid conditions that complicate the diagnosis or treatment ${ }^{18}$ (eg, cognitive impairment), and decreased social support network. Compared with younger adults, older adults are less likely to report or perceive their drug/alcohol as excessive or problematic. ${ }^{19,20}$

The challenge to recognize substance abuse among older adults and the elderly is exacerbated by the shortage of screening instruments designed specifically for this age group. ${ }^{21}$ There are currently no validated screening abuse drugs or tools designed specifically for seniors. ${ }^{22}$ It is complementary studies required to develop screening instruments for drug abuse, ${ }^{23}$ which are valid for older adults. Diagnostic time, the use and abuse of substances, involves using dependence criteria of the Diagnostic and Statistical Manual of Mental Disorders (DSM) ${ }^{24}$ which are basically physiological symptoms (tolerance and withdrawal), which may be more subtle or prolonged in the elderly due to physiological changes of aging. Second, the decline in physical health, cognitive impairment, or conditions that may be altering your attention and memory or interpretations of other symptoms of drug dependency, compulsive behaviors primarily drug use (quantities taking more larger or longer, a greater amount of time spent using or recovering from the effects, reduced activities, the inability to reduce use, continued use despite problems as a result).

Third, due to retirement, loss of family, the reduction of social support networks, legal problems, relationship problems with family and environment may be less applicable to older adult's people more young. Given these age-related changes, there is a need to evaluate the usefulness of the review (or down) the diagnostic threshold to focus more on the pattern and frequency of drug use for older adults. ${ }^{9,25}$

\section{Acknowledgments}

None.

\section{Conflicts of interest}

Author declares there are no conflicts of interest.

\section{Funding}

None.

\section{References}

1. Colliver JD, Compton WM, Gfroerer JC, et al. Projecting drug use among aging baby boomers in 2020. Ann Epidemiol . 2006;16(4):257-265.

2. Blazer DG, Wu LT. The epidemiology of substance use and disorders Among middle-aged and elderly community adults: National survey on drug use and health. Am J Geriatr Psychiatry. 2009;17(3):237-245.

3. Simoni-Wastila L, Yang HK. Psychoactive drug abuse in older adults. Am J Geriatr Pharmacother. 2006;4(4):380-394.

4. Dowling GJ, Weiss SR, Condon TP. Drugs of abuse and the aging brain. Neuropsychopharmacology. 2008;33(2):209-218.

5. Schlaerth KR, Splawn RG, Ong J, et al. Change in the pattern of illegal drug use in an inner city Population over 50: An observational study. $J$ Addict Dis. 2004;23(2):95-107.

6. Culberson JW, Ziska M. Prescription drug misuse / abuse in the elderly. Geriatrics. 2008;63(9):22-31.

7. Gfroerer J, Penne M, Pemberton M, et al. Substance abuse treatment need in 2020. Among older adults: The impact of the aging baby-boom cohort. Drug Alcohol Depend. 2003;69(2):127-135.

8. Han B, Gfroerer JC, Colliver JD, et al. Substance use disorder among older adults in the United States in 2020. Addiction. 2009;104(1):88-96.

9. King CJ, Van Hasselt VB, Segal DL, et al. Diagnosis and assessment of substance abuse in older adults: Current Strategies and issues. Addict Behav. 1994;19(1):41-55.

10. Llorente MD, David D, Golden AG, et al. Defining patterns of benzodiazepine use in older adults. Journal of Geriatric Psychiatry and Neurology. 2000;13(3):150-160.

11. American Geriatrics Society. Clinical guidelines for alcohol-use disorders in older adults. Retrieved from www.americangeriatrics.org American Psychiatric Association. Diagnostic and statistical Manual of Mental disorders. (2000). Washington, DC, USA. 2003.

12. Degenhardt L, Dierker L, Chiu WT, et al. Evaluating the drug use "gateway" theory using crossnational data: Consistency and associations of the order of initiation of drug use Among Participants in the WHO World Mental Health Surveys. Drug Alcohol Depend. 2010;108(1-2):84-97.

13. Voyer P, Préville M, Roussel ME, et al. Factors Associated With benzodiazepine dependence Among community-dwelling seniors. $J$ Community Health Nurs. 2009;26(3):101-113.

14. Rosen D, Smith ML, Reynolds CF III . The Prevalence of Mental and physical health disorders among older methadone patients. Am J Geriatr Psychiatry. 2008;16(6):488-497.

15. Voyer P, Préville M, Cohen D, et al. The Prevalence of benzodiazepine dependence Among community-dwelling older adult users in Quebec según typical and atypical criteria. Can J Aging. 2010;29(9):205-213.

16. Miller NS, Belkin BM, Gold MS. Alcohol and drug dependence Among the elderly: Epidemiology, diagnosis, and treatment. Compr Psychiatry. 1991;32(2):153-165.

17. Préville M, Boyer R, Grenier S, et al. The epidemiology of psychiatric disorders in Quebec's older adult Population. Can J Psychiatry. 2008; 53(12):822-832.

18. Arndt S, Gunter TD, Acion L. Older admissions to substance abuse treatment in 2001. Am J Geriatr Psychiatry. 2005;13(5):385-392. 
19. Satre DD, Blow FC, Chi FW, et al. Gender expats in seven-year Alcohol and drug treatment outcomes Among older adults. Addiction. 2007; 16:216-221.

20. Satre DD, Mertens JR, Arean PA, et al. Five-year alcohol, and drug treatment outcomes of older adults versus middle-aged and younger adults in a managed care program. Addiction. 2004;99(10):1286-1297.

21. Blazer DG, Wu LT. Nonprescription use of pain relievers by middleaged and elderly adults living Community-: National Survey on Drug Use and Health. Am J Geriatr Psychiatry. 2009;57(7):1252-1257.
22. Schonfeld L, King-Kallimanis BL, Duchene DM, et al. Screening and brief intervention for substance misuse among older adults: The Florida BRITE project. Am J Public Health. 2010;100(1):108-114.

23. Manchikanti L. National drug monitoring policy and prescription drug abuse: Facts and fallacies. Pain Physician. 2007;10(3):399-424.

24. Schatzberg AF. Why is DSM-5 Being delayed? Psychiatric News. 2010; 45: 3 .

25. Atkinson RM. Aging and Alcohol use disorders: Diagnostic issues in the elderly. International Psychogeriatrics. 1990;2(1):55-72. 